\title{
Premium Pricing of Liability Insurance Using Random Sum Model
}

\section{Mujiati Dwi Kartikasari}

\author{
Program Studi Statistika, Universitas Islam Indonesia, Jalan Kaliurang Km 14,5 Sleman, \\ Yogyakarta \\ mujiatikartikasari@uii.ac.id
}

\begin{abstract}
Premium pricing is one of important activities in insurance. Nonlife insurance premium is calculated from expected value of historical data claims. The historical data claims are collected so that it forms a sum of independent random number which is called random sum. In premium pricing using random sum, claim frequency distribution and claim severity distribution are combined. The combination of these distributions is called compound distribution. By using liability claim insurance data, we analyze premium pricing using random sum model based on compound distribution.
\end{abstract}

Keywords: premium, nonlife insurance, random sum, claim frequency, claim severity, compound distribution.

\begin{abstract}
ABSTRAK
Penentuan premi merupakan salah satu kegiatan penting dalam asuransi. Premi asuransi umum dihitung dari nilai harapan data historis klaim asuransi. Data historis klaim asuransi dikumpulkan sehingga membentuk jumlahan peubah-peubah acak yang saling bebas, atau disebut jumlah acak. Dalam penentuan premi dengan model jumlah acak, distribusi frekuensi klaim dikombinasikan dengan distribusi severitas klaim. Kombinasi distribusi tersebut disebut distribusi campuran. Dengan menggunakan data klaim asuransi tanggung gugat, dilakukan analisis perhitungan premi dengan model jumlah acak berdasarkan distribusi campuran.
\end{abstract}

Kata Kunci: premi, asuransi umum, jumlah acak, frekuensi klaim, severitas klaim, distribusi campuran.

\section{Pendahuluan}

Bisnis asuransi semakin

berkembang dari tahun ke tahun. Hal ini dikarenakan setiap bidang kehidupan selalu berhubungan dengan risiko. Risiko dapat terjadi tanpa diduga-duga. Salah satu upaya untuk meminimalkan risiko adalah dengan asuransi. Asuransi merupakan suatu kegiatan pemindahan risiko untuk mencegah terjadinya kerugian besar yang disebabkan oleh risiko-risiko tertentu, seperti risiko kematian, kecelakaan, sakit, kerusakan, kebakaran, kehilangan harta, dan lain sebagainya.

Asuransi dibedakan menjadi dua jenis, yaitu asuransi jiwa (life insurance) dan asuransi non-jiwa (nonlife insurance). Pada asuransi jiwa, risiko yang dijamin oleh perusahaan asuransi adalah risiko kematian sedangkan pada asuransi nonjiwa, risiko yang dijamin oleh perusahaan asuransi bermacam-macam tergantung pada jenis yang diasuransikan. Asuransi non-jiwa sering disebut juga sebagai asuransi umum (general insurance). Salah 
satu jenis asuransi non-jiwa yaitu asuransi tanggung gugat.

$$
\text { Asuransi tanggung gugat }
$$
merupakan produk asuransi yang memberikan jaminan perlindungan kepada tertanggung terhadap risiko yang timbul karena adanya tuntutan dari pihak lain (pihak ketiga) sehubungan dengan aktifitas personal/perusahaan milik tertanggung. Secara umum, hal yang dijamin oleh asuransi tanggung gugat adalah kewajiban tertanggung membayar ganti rugi atau kompensasi atas kerugian yang diderita oleh pihak ketiga.

Premi asuransi merupakan sejumlah uang yang harus dibayarkan sebagai kewajiban dari tertanggung atas keikutsertaannya di asuransi. Besarnya premi telah ditentukan oleh perusahaan asuransi dengan memperhatikan keadaan pihak tertanggung. Pembayaran premi dapat dilakukan dalam bentuk premi tunggal atau premi berkala. Premi tunggal (single premium) adalah premi yang dibayarkan sekali saja di awal bergabungnya tertanggung di perusahaan asuransi sedangkan premi berkala (regular premium) adalah premi yang dibayarkan secara berkala dalam periode tertentu, misalnya per bulan, per kuartal, per semester, atau per tahun.

Penentuan premi merupakan salah satu pokok utama dalam asuransi. Premi dihitung dari nilai harapan risiko atau kerugian yang akan dijamin oleh perusahaan asuransi. Untuk menghitung nilai harapan premi, perlu diketahui distribusi dari data risiko, baik jumlah (frekuensi) risiko maupun besar (severitas) risiko. Data risiko dalam perusahaan asuransi biasanya berupa data klaim yang dibayarkan oleh perusahaan asuransi kepada tertanggung.

Berbagai penelitian mengenai penentuan premi telah banyak dilakukan. Brockman dan Wright (1992), Renshaw (1994), Haberman dan Renshaw (1996), dan Rosenlund (2013) menggunakan prinsip penentuan premi dengan mengkombinasikan nilai harapan frekuensi klaim dan severitas klaim. Dalam makalah ini, terlebih dahulu akan ditentukan distribusi frekuensi klaim dan distribusi severitas klaim. Selanjutnya, kedua distribusi tersebut dikombinasikan sehingga dihasilkan distribusi campuran. Distribusi campuran merupakan distribusi dari jumlahan peubah acak atas sejumlah pembayaran klaim, atau disebut jumlah acak. Berdasarkan distribusi campuran yang telah diperoleh, dihitung perkiraan premi murni dengan menghitung nilai harapannya.

Makalah ini disusun sebagai berikut. Bagian 2 mengulas pengertian jumlah acak beserta mean dan variansinya. Distribusi campuran dibahas dalam bagian 3. Bagian 4 mengulas fungsi 
mean residual life. Studi kasus diuraikan pada bagian 5 dan kesimpulan dikemukakan pada bagian terakhir makalah ini.

\section{Jumlah Acak}

Jumlah acak merupakan jumlahan peubah-peubah acak saling bebas yang dinyatakan sebagai

$$
S=X_{1}+X_{2}+\ldots+X_{N}, \quad N=0,1,2, \cdots
$$

dimana $S=0$ ketika $N=0$ (Klugman, Panjer, dan Willmot, 2004). Peubah acak $N$ menyatakan frekuensi klaim yang mempunyai fungsi massa peluang $\operatorname{Pr}(N=n)$ dengan mean $E(N)$ dan variansi $\operatorname{Var}(N)$. Peubah-peubah acak $X_{1}, X_{2}, \cdots, X_{N}$ menyatakan severitas klaim dengan mean $E(X)$ dan variansi $\operatorname{Var}(X)$.

Asumsi-asumsi yang harus dipenuhi jumlah acak $S$ antara lain (Klugman, Panjer, dan Willmot, 2004):

1. bersyarat pada $N=n$, peubahpeubah acak $X_{1}, X_{2}, \ldots, X_{N}$ saling bebas dan berdistribusi identik,

2. bersyarat pada $N=n$, distribusi dari peubah-peubah acak $X_{1}, X_{2}, \ldots, X_{N}$ tidak bergantung pada $n$,

3. distribusi dari $N$ tidak tergantung pada nilai-nilai $X_{1}, X_{2}, \ldots$
Berdasarkan asumsi-asumsi jumlah acak $S$, mean dan variansi $S$ dapat ditentukan sebagai berikut:

$$
\begin{aligned}
E[S] & =E[E[S \mid N]] \\
& =\sum_{n=0}^{\infty} E\left[X_{1}+X_{2}+\cdots+X_{N} \mid N=n\right] \operatorname{Pr}[N=n] \\
& =\sum_{n=0}^{\infty} E\left[X_{1}+X_{2}+\cdots+X_{n} \mid N=n\right] \operatorname{Pr}[N=n] \\
& =\sum_{n=0}^{\infty} E\left[X_{1}+X_{2}+\cdots+X_{n}\right] \operatorname{Pr}[N=n] \\
& =\sum_{n=0}^{\infty} n E[X] \operatorname{Pr}[N=n] \\
& =E[X] \sum_{n=0}^{\infty} n \operatorname{Pr}[N=n] \\
& =E[X] E[N]
\end{aligned}
$$

dan

$$
\begin{aligned}
\operatorname{Var}[S] & =E[\operatorname{Var}[S \mid N]]+\operatorname{Var}[E[S \mid N]] \\
& =E[N \operatorname{Var}[X]]+\operatorname{Var}[N E[X]] \\
& =\operatorname{Var}[X] E[N]+[E[X]]^{2} \operatorname{Var}[N]
\end{aligned}
$$

\section{Distribusi Campuran}

Seluruh uraian mengenai distribusi campuran diambil dari Klugman, Panjer, dan Willmot (2004). Distribusi campuran adalah distribusi dari jumlah acak $S$. Tahapan untuk membangun distribusi $S$ adalah sebagai berikut:

1. Membangun suatu model untuk distribusi dari $N$ berdasarkan pada data.

2. Membangun suatu model untuk distribusi dari $X_{j}$ berdasarkan pada data.

3. Menggunakan kedua model di atas untuk mendapatkan distribusi dari $S$. 
Distribusi campuran dari jumlah acak $S$ adalah

$$
\begin{aligned}
F_{S}(x) & =\operatorname{Pr}(S \leq x) \\
& =\sum_{n=0}^{\infty} p_{n} \operatorname{Pr}(S \leq x \mid N=n) \\
& =\sum_{n=0}^{\infty} p_{n} F_{X}^{*_{n}}(x)
\end{aligned}
$$

dimana $F_{X}(x)=\operatorname{Pr}(X \leq x) \quad$ merupakan fungsi distribusi dari $X_{j}$ dan $p_{n}=\operatorname{Pr}(N=n)$ merupakan fungsi massa peluang dari $N$. Fungsi peluang untuk distribusi campuran $S$ adalah

$$
f_{S}(x)=\sum_{n=0}^{\infty} p_{n} f_{X}^{*_{n}}(x)
$$

$$
\text { Pada Persamaan (1), } \quad F_{X}^{*^{n}}(x)
$$

menyatakan konvolusi lipat $n$ dari fungsi distribusi kumulatif $X$. Fungsi ini dapat diperoleh dari

$$
F_{X}^{* 0}(x)= \begin{cases}0, & x<0 \\ 1, & x \geq 0\end{cases}
$$

dan untuk $k=1,2, \ldots$,

$$
F_{X}^{* k}(x)=\int_{-\infty}^{\infty} F_{X}^{*(k-1)}(x-y) d F_{X}(y)(3)
$$

Jika $X$ merupakan peubah acak kontinu dengan peluang nol pada nilai-nilai negatif, maka Persamaan (3) menjadi

$$
F_{X}^{* k}(x)=\int_{0}^{x} F_{X}^{*(k-1)}(x-y) f_{X}(y) d y
$$

untuk $k=2,3, \ldots$ Untuk $k=1$, persamaan tersebut menjadi $F_{X}^{* 1}(x)=F_{X}(x)$. Fungsi densitas peluangnya adalah

$$
f_{X}^{* k}(x)=\int_{0}^{x} f_{X}^{*(k-1)}(x-y) f_{X}(y) d y
$$

untuk $k=2,3, \ldots$. Pada kasus peubah acak diskrit dengan peluang positif pada $0,1,2, \ldots$, Persamaan (3) menjadi

$$
F_{X}^{* k}(x)=\sum_{y=0}^{x} F_{X}^{*(k-1)}(x-y) f_{X}(y)
$$

untuk $x=0,1, \ldots$, dan $k=2,3, \ldots$. Fungsi peluang yang bersesuaiannya adalah

$$
f_{X}^{* k}(x)=\sum_{y=0}^{x} f_{X}^{*(k-1)}(x-y) f_{X}(y)
$$

untuk $x=0,1, \ldots, k=2,3, \ldots$.

\section{Fungsi Mean Residual Life}

Fungsi mean residual life dapat digunakan untuk melihat karakteristik dari ekor (tail) distribusi. Ekor distribusi adalah bagian dari distribusi yang ada kaitannya dengan nilai yang besar pada peubah acak (Klugman, Panjer, dan Willmot, 2004). Ketika memilih model distribusi untuk data risiko atau kerugian, ukuran ekor dapat membantu dalam penentuan model yang terbaik.

Untuk peubah acak severitas klaim $X$, fungsi mean residual life merupakan nilai harapan dari pembayaran per klaim dengan deduktibel sebesar $x$, dimana $X>x$, dinyatakan dengan (Klugman, Panjer, dan Willmot, 2004)

$$
\begin{aligned}
e(x) & =E(X-x \mid X>x) \\
& =\frac{\int_{x}^{\infty}\{1-F(u)\} d u}{1-F(x)} .
\end{aligned}
$$

Dalam praktik, fungsi mean residual life $e$ diestimasi dengan $\hat{e}_{n}$ berdasarkan 
perwakilan sampel $x_{1}, x_{2}, \ldots, x_{n}$ yang selanjutnya disebut sebagai fungsi empirical mean residual life. Guess dan Proschan (1985) mendefinisikan fungsi empirical mean residual life sebagai berikut,

$$
\hat{e}_{n}(x)=\frac{\sum_{i=k+1}^{n}\left(x_{i}-x\right)}{n-k}
$$

untuk $x \in\left(x_{k}, x_{(k+1)}\right)$ dan $k=0,1, \ldots, n-1$.

\section{Studi Kasus}

Data yang digunakan dalam studi kasus adalah data total klaim asuransi tanggung gugat tahun 2012-2014. Data tersebut berisi informasi mengenai frekuensi klaim yang menunjukkan banyaknya kejadian klaim dan severitas klaim yang menunjukkan besar pembayaran klaim yang dilakukan oleh perusahaan asuransi. Data klaim asuransi tanggung gugat disajikan pada Gambar 1 dan Gambar 2.

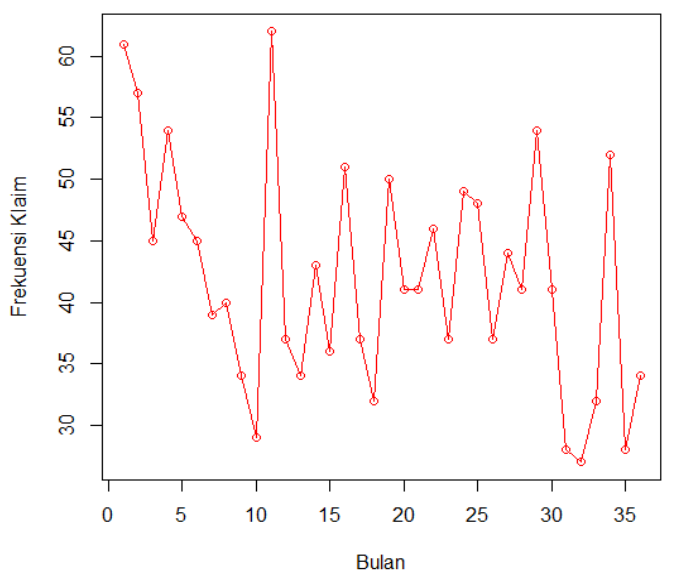

Gambar 1. Frekuensi Klaim Asuransi Tanggung Gugat

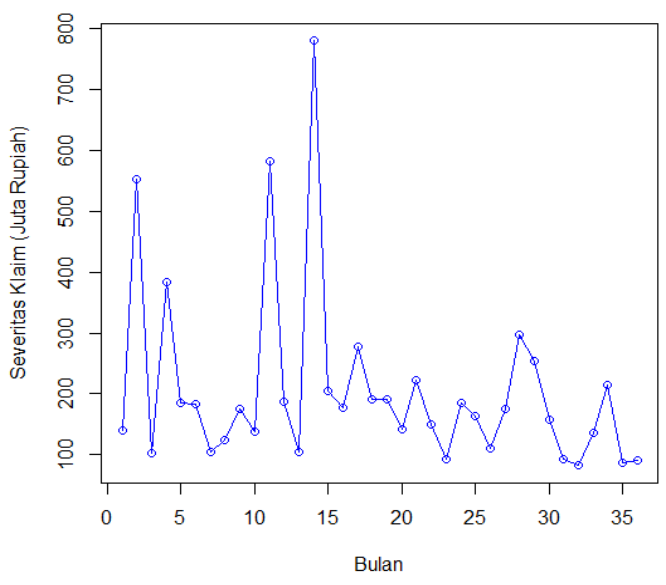

Gambar 2. Severitas Klaim Asuransi Tanggung Gugat

Berdasarkan data yang disajikan pada Gambar 1 dan Gambar 2, selanjutnya akan dilakukan estimasi terhadap distribusi frekuensi dan severitas klaim. Distribusi geometri, negatif binomial, binomial dan Poisson merupakan distribusi-distribusi yang umum digunakan untuk memodelkan frekuensi klaim sedangkan distribusi eksponensial, Gamma, Weibull, dan Pareto merupakan distribusi-distribusi yang umum digunakan untuk memodelkan severitas klaim (Tse, 2009). Ada beberapa tambahan distribusi lain yang dapat digunakan untuk memodelkan severitas klaim, seperti distribusi lognormal dan distribusi Burr (Burnecki, Janczura, dan Weron, 2010).

Distribusi frekuensi klaim akan disimpulkan berdasarkan nilai uji statistik dari distribusi geometri, negatif binomial, dan Poisson. Adapun hasil estimasi dan uji statistik distribusi frekuensi klaim 
asuransi tanggung gugat disajikan pada Tabel 1 dan Tabel 2.

Tabel 1. Estimasi Parameter Calon Distribusi Frekuensi Klaim Asuransi Tanggung Gugat

\begin{tabular}{|c|c|c|c|}
\hline Distribusi & \multicolumn{2}{|c|}{$\begin{array}{c}\text { Estimasi } \\
\text { Parameter }\end{array}$} & $\begin{array}{c}\text { Log- } \\
\text { Likelihood }\end{array}$ \\
\hline Geometri & $p$ & 0,02 & $-171,0048$ \\
\hline Neg. Binomial & $p$ & $\begin{array}{r}43,22 \\
0,51\end{array}$ & $-130,1730$ \\
\hline Poisson & $\lambda$ & 42,03 & $-135,4721$ \\
\hline
\end{tabular}

Tabel 2. Tabel Statistik Calon Distribusi Frekuensi Klaim Asuransi Tanggung Gugat

\begin{tabular}{lrr}
\hline \multirow{2}{*}{ Distribusi } & \multicolumn{2}{c}{ Chi-Squared Test } \\
\cline { 2 - 3 } & $\begin{array}{c}\text { Nilai } \\
\text { Statistik }\end{array}$ & $\begin{array}{c}\text { p-value } \\
(\alpha=0,05)\end{array}$ \\
\hline Geometri & 693,75 & 0,2293 \\
Neg. Binomial & 446,50 & 0,6655 \\
Poisson & 520,00 & 0,3238 \\
\hline
\end{tabular}

Rumusan uji hipotesis untuk menguji kecocokan distribusi frekuensi klaim adalah sebagai berikut:

$H_{0}$ : Data berasal dari populasi dengan distribusi tertentu,

$H_{1}$ : Data tidak berasal dari populasi dengan distribusi tertentu.

Nilai p-value dari uji Chi-Squared baik untuk distribusi geometri, negatif binomial, dan Poisson lebih besar dari 0,05 sehingga keputusan untuk hipotesis di atas yaitu gagal menolak $H_{0}$, yang berarti data klaim asuransi tanggung gugat berasal dari populasi dengan distribusi tertentu. Berdasarkan nilai loglikelihood dari ketiga calon distribusi frekuensi klaim asuransi tanggung gugat, nilai loglikelihood dari distribusi geometri merupakan nilai yang paling kecil. Oleh karena itu, dapat disimpulkan bahwa distribusi geometri adalah distribusi terbaik dalam memodelkan frekuensi klaim asuransi tanggung gugat.

Adapun distribusi untuk severitas klaim akan disimpulkan berdasarkan nilai uji statistik dari distribusi eksponensial, Gamma, Weibull, Pareto, lognormal, dan distribusi Burr. Namun, sebelum melakukan pengujian, terlebih dahulu akan digambarkan plot fungsi empirical mean residual life berdasarkan Persamaan (4).

Berdasarkan Gambar 3, plot fungsi empirical mean residual life dari distribusi Gamma, lognormal, dan distribusi Burr mempunyai pola yang hampir sama dengan plot fungsi empirical mean residual life severitas klaim asuransi tanggung gugat. Dengan demikian, distribusi Gamma, lognormal, dan distribusi Burr dijadikan sebagai calon distribusi severitas klaim asuransi tanggung gugat. Hasil estimasi dan uji statistik distribusi severitas klaim asuransi tanggung gugat disajikan pada Tabel 3 dan Tabel 4. 
EMRL Severitas Klaim

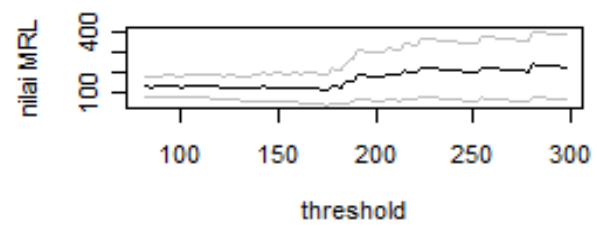

EMRL Dist.Gamma

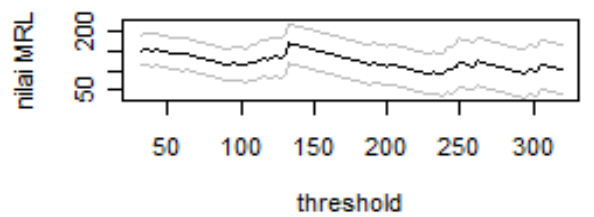

EMRL Dist.Lognormal

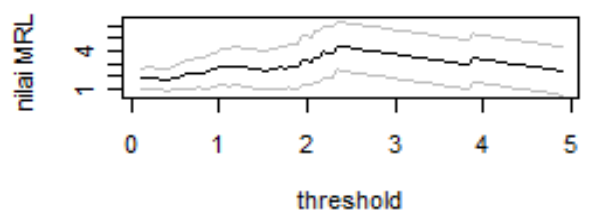

EMRL Dist.Burr

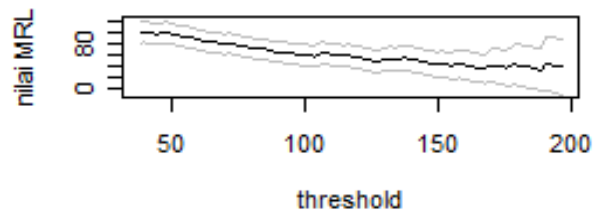

EMRL Dist.Eksponensial

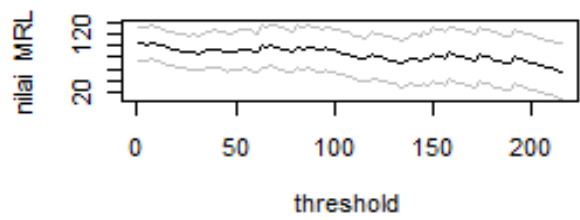

EMRL Dist.Pareto

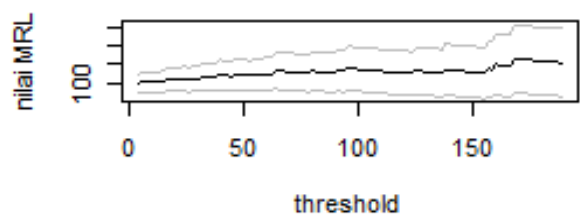

EMRL Dist.Weibull

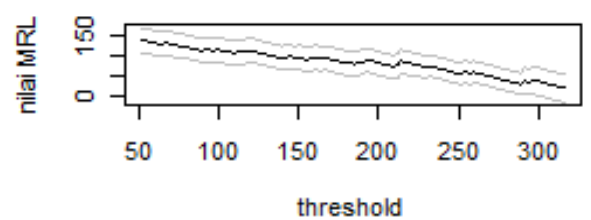

Gambar 3. Fungsi Empirical Mean Residual Life Distribusi Severitas Klaim

Tabel 3. Estimasi Parameter Calon Distribusi Severitas Klaim Asuransi Tanggung Gugat

\begin{tabular}{|c|c|c|}
\hline Distribusi & $\begin{array}{c}\text { Estimasi } \\
\text { Parameter }\end{array}$ & $\begin{array}{c}\text { Log- } \\
\text { Likelihood }\end{array}$ \\
\hline \multirow{2}{*}{ Gamma } & 1,949 & \multirow{2}{*}{$-220,1581$} \\
\hline & 105,9 & \\
\hline \multirow{3}{*}{ Lognormal } & 5,164 & \multirow{3}{*}{$-214,1584$} \\
\hline & 0,531 & \\
\hline & 0,370 & \\
\hline \multirow[t]{2}{*}{ Burr } & 5,718 & \multirow[t]{2}{*}{$-211,6649$} \\
\hline & 118,2 & \\
\hline
\end{tabular}

menguji kecocokan distribusi severitas klaim adalah sebagai berikut:

$H_{0}$ : Data berasal dari populasi dengan distribusi tertentu,
$H_{1}$ : Data tidak berasal dari populasi dengan distribusi tertentu.

Tabel 4. Tabel Statistik Calon Distribusi Severitas Klaim Asuransi Tanggung Gugat

\begin{tabular}{lrr}
\hline \multirow{2}{*}{ Distribusi } & \multicolumn{2}{c}{ Kolmogorov-Smirnov } \\
& \multicolumn{2}{c}{ Test } \\
\cline { 2 - 3 } & $\begin{array}{c}\text { Nilai } \\
\text { Statistik }\end{array}$ & $\begin{array}{c}\text { p-value } \\
(\alpha=0,05)\end{array}$ \\
\hline Gamma & 0,1936 & 0,1174 \\
Lognormal & 0,1574 & 0,3018 \\
Burr & 0,1109 & 0,7266 \\
\hline
\end{tabular}

Nilai p-value dari uji KolmogorovSmirnov baik untuk distribusi Gamma, lognormal dan Burr lebih besar dari 0,05 
sehingga keputusan untuk hipotesis di atas yaitu gagal menolak $H_{0}$, yang berarti data klaim asuransi tanggung gugat berasal dari populasi dengan distribusi tertentu. Berdasarkan nilai loglikelihood dari ketiga calon distribusi severitas klaim asuransi tanggung gugat, nilai loglikelihood dari distribusi Gamma merupakan nilai yang paling kecil. Oleh karena itu, dapat disimpulkan bahwa distribusi Gamma adalah distribusi terbaik dalam memodelkan severitas klaim asuransi tanggung gugat.

Berdasarkan estimasi distribusi frekuensi klaim dan severitas klaim yang telah diperoleh, selanjutnya akan ditentukan nilai premi asuransi tanggung gugat menggunakan estimasi distribusi campuran. Estimasi distribusi premi asuransi tanggung gugat diperoleh secara numerik menggunakan metode konvolusi. Dengan terlebih dahulu mendiskritkan distribusi Gamma yang merupakan distribusi severitas klaim, kemudian menerapkan Persamaan (2), akan diperoleh distribusi premi asuransi tanggung gugat seperti disajikan pada Gambar 4.

Distribusi premi asuransi tanggung gugat digunakan untuk mengestimasi nilai premi total, yaitu dengan menghitung mean dan variansi dari distribusi tersebut. Estimasi mean dan variansi dari distribusi premi asuransi tanggung gugat disajikan pada Tabel 5.

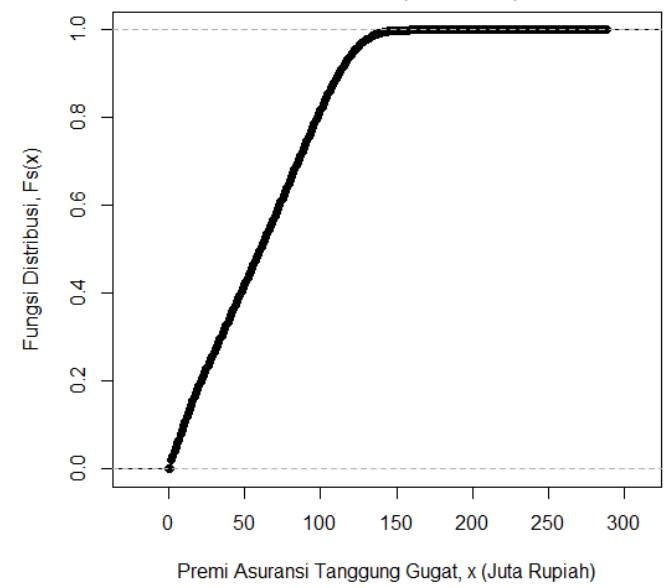

Gambar 4. Fungsi Distribusi Premi Asuransi Tanggung Gugat

Berdasarkan informasi pada Tabel 5, maka perkiraan premi total untuk tahun 2015-2017 sebesar Rp61.410.000,00.

Tabel 5. Estimasi Mean dan Variansi Distribusi Premi Asuransi Tanggung Gugat

\begin{tabular}{lr}
\hline Mean dan Variansi & Nilai Estimasi \\
\hline Mean $E(S)$ & 61,41 \\
Variansi $\operatorname{Var}(S)$ & 1405,51 \\
\hline
\end{tabular}

Nilai premi tersebut berasal dari hasil kali nilai harapan distribusi premi asuransi tanggung gugat dengan satuan severitas klaim. Dengan premi total tersebut, diharapkan perusahaan asuransi dapat memenuhi klaim-klaim yang diajukan dengan asumsi kejadian klaim tahun 2015, 2016, dan 2017 tidak menyimpang dari data klaim tahun 2012 sampai dengan tahun 2014. 


\section{Kesimpulan}

Kesimpulan yang dapat diperoleh berdasarkan analisis studi kasus yang telah dilakukan adalah sebagai berikut:

1. Pemodelan distribusi campuran dari jumlahan peubah acak dilakukan dengan memodelkan data historis dari klaim asuransi.

2. Model distribusi campuran terbentuk dari proses konvolusi berulang antara distribusi frekuensi klaim dan severitas klaim. Hasil perhitungan menggunakan data klaim asuransi tanggung gugat diperoleh bahwa distribusi frekuensi klaim adalah geometri dan distribusi severitas klaim adalah Gamma.

3. Perhitungan perkiraan premi total untuk tahun 2015-2017 menggunakan data klaim asuransi tanggung gugat tahun 2012 sampai dengan 2014 dengan model jumlah acak berdasarkan distribusi campuran adalah sebesar Rp61.410.000,00. Dengan premi total tersebut, diharapkan perusahaan asuransi dapat memenuhi klaim-klaim yang diajukan dengan asumsi kejadian klaim tahun 2015, 2016, dan 2017 tidak menyimpang dari data klaim tahun 2012 sampai dengan tahun 2014.

\section{Pustaka}

Brockman M. H, dan Wright, T. S, 1992, Statistical Motor Rating: Making Effective Use of Your Data. Journal of the Institute of Actuaries, 119(3), 457-543.
Burnecki, Krzysztof, Janczura, Joanna, dan Weron, Rafal, 2010, Building Loss Models, SFB 649 Economic Risk, ISSN 1860-664, HumboldtUniversität zu Berlin.

Guess, F dan Proschan, F, 1985, Mean Residual Life: Theory and Applications, FSU Statistics Report M702 AFOSR Technical Report, 85-178.

Haberman S dan Renshaw, A. E, 1996. Generalized Linear Models and Actuarial Science. The Statistician. 45(4), 407-436.

Klugman, A. Stuart, Panjer, Harry H., dan Willmot, Gordon E., 2004, Loss Models From Data to Decisions Second Edition, 48, 140, John Wiley \& Sons, New York, USA.

Renshaw, Arthur E, 1994, Modelling the Claims Process in the Presence Covariates, ASTIN Bulletin, 24(2), 265-285.

Rosenlund, Stig, 2014, Integrating Ordinary GLM with Credibility in a Compound Poisson Model, Lecture in Indonesia November 2014, diselenggarakan oleh Institut Teknologi Bandung dan Universitas Gadjah Mada, Indonesia.

Tse, Yiu Kuen, 2009, Nonlife Actuarial Models, 6, 49, Cambridge University Press, New York, USA. 